\title{
An atypical presentation of adult ileocolic intussusception
}

\author{
This article was published in the following Dove Press journal: \\ Open Access Surgery \\ 8 December 2010 \\ Number of times this article has been viewed
}

\section{Emeka I Udeh' \\ Callistus O Amu' \\ Nuhu K Dakum ${ }^{2}$ \\ Samuel A R Ohayi' \\ Benjamin O Ayogu' \\ Chukwudi O Madu' \\ 'Enugu State University of Technology Teaching Hospital, Park Lane, Enugu \\ State; ${ }^{2}$ Jos University Teaching \\ Hospital, Jos, Plateau State, Nigeria}

Correspondence: Emeka Ihechi Udeh Department of Surgery, College of Medicine, ESUT Teaching Hospital, Parklane, PMB I030, Enugu 4002I2, Nigeria

$\mathrm{Tel}+23480650$ I 4026

Email ihechiudeh@yahoo.com
Abstract: Adult intussusception is a rare condition usually associated with a lead point. However, $8 \%-20 \%$ of cases are idiopathic. We describe here the case of a 56 -year-old Nigerian male who presented to the accident and emergency unit with features of acute intestinal obstruction. The findings at laparotomy were ileocolic intussusception without a lead point. A segment of the terminal ileum was nonviable. A right hemicolectomy with ileocolic anastomosis was performed, and the resulting specimen sent for histologic examination which confirmed no extra- or intraluminal lesion. Two years of postoperative evaluation was normal. This report further reiterates the fact that adult intussusception could be idiopathic (without a lead point) and could present as acute intestinal obstruction. Early recognition is necessary to facilitate timely intervention before the onset of gangrene, so as to improve prognosis.

Keywords: atypical presentation, adult, ileocolic, intussusception

\section{Introduction}

Intestinal intussusception is common in children, usually in infants between four and 10 months of age. However, there are reported cases of adult intestinal intussusception. The first reported case was in 1674 by Barbette of Amsterdam, ${ }^{1}$ and was further described in a detailed report by John Hunter ${ }^{2}$ in 1789. Adult intussusception is considered a rare condition, accounting for $5 \%$ of all cases of intussusception and almost $1 \%-5 \%$ of bowel obstruction cases. ${ }^{3,4}$ It is usually caused by organic lesions, ${ }^{5}$ but $8 \%-20 \%$ of cases are idiopathic without a lead point. Here we present a case of adult ileocolic intussusception in which no lead point was identified.

\section{Case report}

The patient was a 56-year-old man who presented to our accident and emergency unit with a four-day history of abdominal pains, vomiting, abdominal distension, and constipation. The abdominal pain was of sudden onset following a bout of alcohol consumption the previous night. The pain was colicky in nature, generalized, and later became continuous. It was aggravated by movement. He vomited six times before presentation. The vomitus was projectile and contained recently ingested food. The quantity of the vomitus was about $500 \mathrm{~mL}$. There was associated constipation to both feces and gas two days before presentation. Also, there was associated loss of appetite and weakness. He has not had surgery in the past. He was not a known diabetic or hypertensive. He was not married, was a secondary school teacher, a smoker, and consumed alcohol regularly. 
On examination, he looked acutely ill, and was dehydrated and pale, but afebrile $\left(36.2^{\circ} \mathrm{C}\right)$. The abdomen was distended but moved with respiration. There was tenderness in the iliac fossae and hypogastric region. There was guarding but no rigidity. The percussion note was resonant and bowel sounds were hypoactive. The rectum on digital examination was empty. Examination of the chest revealed no abnormality. The pulse rate was 100 beats/minute and regular, with a supine blood pressure of 100/70 mmHg. An assessment of mechanical intestinal obstruction with dehydration was made. A plain abdominal radiograph (lateral decubitus and supine) showed multiple air fluid levels and dilated loops of large and small bowel. An abdominal ultrasound scan showed dilated loops of bowel with no free fluid within the peritoneal cavity. Serum biochemistry showed elevated urea $(9.3 \mathrm{mmol} / \mathrm{L})$ and serum creatinine $(442.5 \mu \mathrm{mol} / \mathrm{L})$, and normal levels of potassium, sodium, bicarbonate, and chloride. Hematocrit was $28 \%$. The consideration at this point was mechanical intestinal obstruction with imminent peritonitis. He was commenced on broad-spectrum antibiotics and adequately rehydrated with intravenous fluid.

Findings at exploratory laparotomy were ileocolic intussusception (12 cm of nonviable terminal ileum telescoping into the ascending colon, see Figure 1). He underwent a limited right hemicolectomy and an ileocolic anastomosis. The immediate postoperative period was uneventful. The histology report revealed no extraluminal or intraluminal lesion. Two years of follow-up have been uneventful.

\section{Discussion}

Adult intestinal intussusception affects mainly the small intestine $(52 \%-55 \%)$, while the colon is affected in $38 \%-45 \%$ of cases. ${ }^{6}$ Various methods have been applied in the classification of intussusception. Based on location, it has been classified into four categories, ie, enteroenteric, colocolic, ileocolic, and ileocecal. ${ }^{6,7}$ In addition, based on etiology, adult intussusception has been classified as benign, malignant, and idiopathic. In the small intestine, an intussusception can be secondary either to the presence of intra- or extraluminal lesions. ${ }^{8}$ On the other hand, intussusception occurring in the large bowel is more likely to have a malignant etiology and accounts for up to $66 \%$ of cases. ${ }^{9,10}$ Although our patient presented with an ileocolic intussusception, no extra- or intraluminal lesion was seen. This atypical presentation is seen in $8 \%-20 \%$ of cases. ${ }^{6}$

Furthermore, the clinical presentation of adult intussusception varies considerably. Various reports in the literature suggest that the signs and symptoms are often
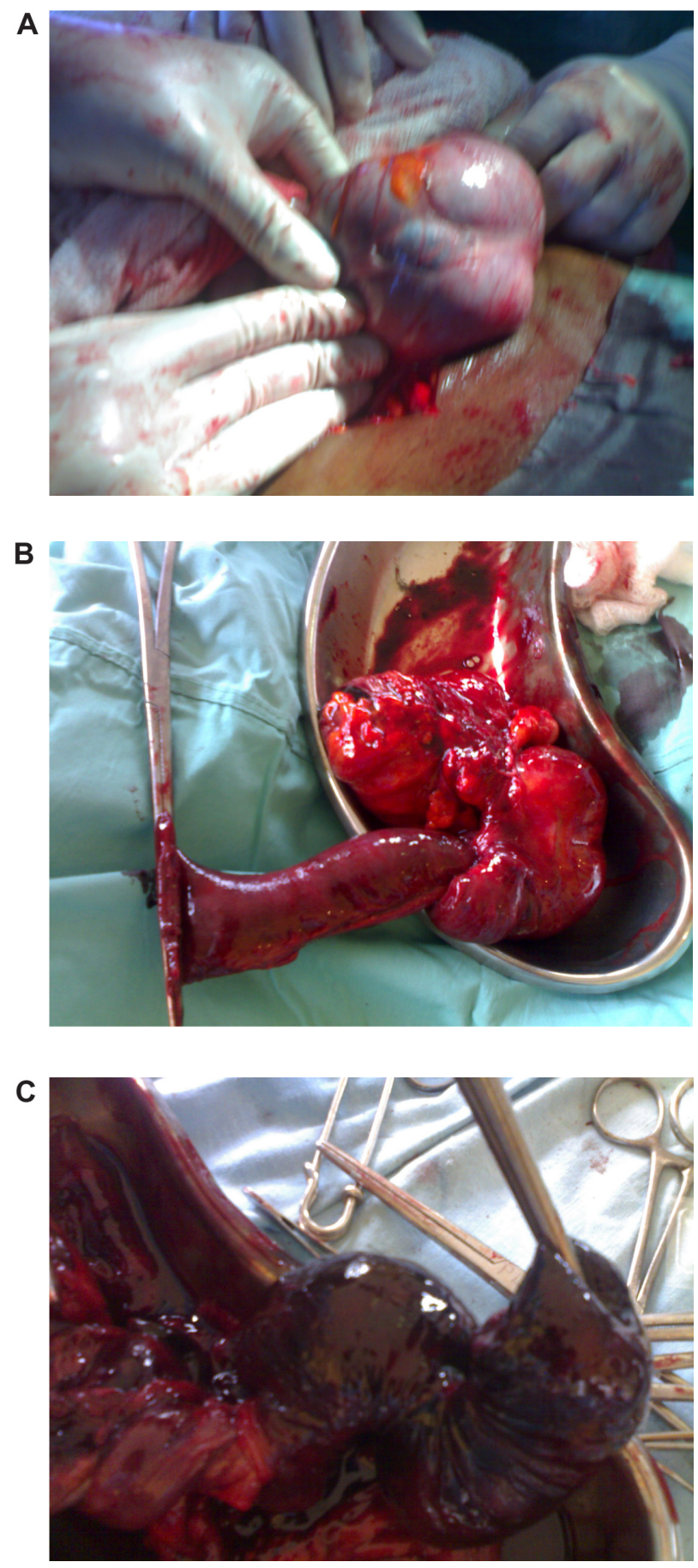

Figure I Intraoperative findings. A) Thickened, congested, and gangrenous terminal ileum, with proximal small bowel obstruction in a 56-year-old man with ileocolic intussusception. B) Surgical specimen after en bloc resection of the terminal ileum and the ascending colon (limited right hemicolectomy). C) Nonviable but intact segment of ileum.

chronic, consistent with partial obstruction and not with acute abdomen. ${ }^{11-13}$ The classic pediatric presentation of acute intussusception (a triad of cramping abdominal pains, bloody diarrhea, and a palpable tender mass) is rare in adults. ${ }^{14}$ Our patient's presentation had characteristics of an acute intestinal obstruction, unlike the reports in the literature. 
In addition, the clinical diagnosis of adult intestinal intussusception is usually difficult because of the variable patterns of presentation. In evaluating such patients, a plain abdominal radiograph is useful as a diagnostic tool in that it demonstrates signs of intestinal obstruction; ${ }^{15}$ when abdominal ultrasonography shows the typical concentric hyperechoic double ring coupled with thickening of the intestinal walls, a diagnosis of colonic intussusception should be considered. ${ }^{16}$ There are situations where only distended loops of bowel would be demonstrated on abdominal ultrasonography without the above typical findings, as was the case in our patient. This is attributed to the presence of massive amounts of air in the distended bowel loops.

Abdominal computed tomography is currently considered to be the most reliable radiologic method to confirm intussusception, with a reported diagnostic accuracy of $58 \%-100 \% .{ }^{17,18}$ The features demonstrated by computed tomography scan include inhomogeneous "target" or "sausage-shaped" soft tissue mass with a layering effect. ${ }^{19} \mathrm{Kim}$ et al reported that abdominal computed tomography scan was able to differentiate intussusception without a lead point from that with a lead point. ${ }^{19}$

Colonoscopy has been used to confirm intussusception in some cases. Its advantage is that it can demonstrate if there is an underlying organic lesion serving as a lead point.

Treatment for adult intestinal intussusception is surgical resection of the involved bowel segments. Intestinal anastomosis after resection or colostomy is the surgeon's prerogative, and is usually determined by the performance status of the patient involved and the extent of disease. Preoperative reduction with barium or air is not recommended as a treatment modality in adults. ${ }^{20,21}$ This is due to the high risk of perforation of the gut and seeding of microorganisms and tumor cells to the peritoneal cavity. ${ }^{22}$

\section{Conclusion}

Adult bowel intussusception is a rare but challenging condition for the surgeon. This case report shows that adult intestinal intussusception may not have a lead point and can present as acute intestinal obstruction. Early recognition is necessary to facilitate timely intervention before the onset of gangrene, so as to improve prognosis.

Open Access Surgery

\section{Publish your work in this journal}

Open Access Surgery is an international, peer-reviewed, open access journal that focuses on all aspects of surgical procedures and interventions. Patient care around the peri-operative period and patient outcomes post surgery are key topics. All grades of surgery from minor cosmetic interventions to major surgical procedures are covered. Novel techniques

\section{Disclosure}

The authors report no conflicts of interest in this work.

\section{References}

1. de Moulin D, Paul Barbette MD. A seventeenth-century Amsterdam author of best-selling textbooks. Bull Hist Med. 1985;59:506-514.

2. Noble I. Master Surgeon: John Hunter. New York, NY: J Messner; 1971.

3. Ozoemena OFN, Mba AU, Mgbor SO, Onuigbo NI. Gastrointestinal Kaposi sarcoma presenting in a Nigerian African with HIV? AIDS. Niger J Clin Pract. 2003;6:117-119.

4. Azar T, Berger DL. Adult intussusception. Ann Surg. 1997;226: 134-138.

5. Weilbaecher D, Bolin JA, Heam D, Ogden N. Intussusception in adults. Review of 160 cases. Am J Surg. 1971;121:531-535.

6. Schiud F, van Gansbeke D, Ansey J. Intussusception in adults. Acta Chir Belg. 1985;859:55-60.

7. Nargoney DM, Sarr MG, Mcllrath DC. Surgical management of intussusception in the adult. Ann Surg. 1981;193:230-236.

8. Ishii M, Teramoto S, Yakabe M, et al. Small intestinal intussusceptions caused by percutaneous endoscopic jejunostomy tube placement. $J \mathrm{Am}$ Geriatr Soc. 2007;5:2093-2094.

9. Begos DG, Sandor A, Modlin IM. The diagnosis and management of adult intussusception. Am J Surg. 1997;173:88-94.

10. Takeuchi K, Tsuzuki $Y$, Sekihara M, et al. The diagnosis and treatment of adult intussusception. J Clin Gastroenterol. 2003;36:18-21.

11. Franc-Law JM, Begin LR, Vasilevsky CA, Gordon PH. The dramatic presentation of lipomata. Report of two cases and review of the literature. Am Surg. 2001;67:491-495.

12. Cossarella D, Clerico G, Rosato L, et al. Lipoma of the colon as an unusual cause of recurring partial intestinal occlusion. Clinical case and review of the literature. Minerva Chir. 1998;53:277-280.

13. Aza T, Berget DL. Adult intussusception. Ann Surg. 1997;226: 134-138.

14. Athanasios M, Anneza Y, Lazaros S, et al. Intussusception of the bowel in adults. World J Gastroenterol. 2009;15:407-411.

15. Colter AM, Cohn I. Intussusception in adults. Am J Surg. 1961;101: 114-120.

16. Alkin C, Sasmaz N, Alkim H, et al. Sonographic findings in intussusception caused by a lipoma in the muscular layer of the colon. J Clin Ultrasound. 2001;29:298-301.

17. Erbil Y, Eminoglu L, Cais A, Berber E. Ileocolic invagination in adults due to caecal carcinoma. Acta Chir Belg. 1997;97:190-191.

18. Gayer G, Apter S, Hofmann C, et al. Intussusception in adults: CT diagnosis. Clin Radiol. 1998;97:190-191.

19. Kim YH, Blake MA, Herisiughani MG, et al. Adult intestinal intussusception: CT appearances and identification of a causative lead point. Radiographics. 2006;26:733-734.

20. Essien LK, Cunningham JD, Aufses AH. Intussusception in adults: Institutional review. J Am Coll Surg. 1999;188:390-395.

21. Knowles MC, Fishmann EK, Kuhlman JE, Bayless TM. Transient intussusception in Crohn's disease. CT evaluation. Radiology. 1989; 170:814.

22. Reijnen HA, Joosten HJ, de Boer HH. Diagnosis and treatment of adult intussusception. Am J Surg. 1989;158:25-28.

\section{Dovepress}

and the utilization of new instruments and materials, including implants and prostheses that optimize outcomes constitute major areas of interest. The manuscript management system is completely online and includes a very quick and fair peer-review system. Visit http://www.dovepress.com/ testimonials.php to read real quotes from published authors. 